\title{
The Embryology of some Anomalous Dicotyledons.
}

\author{
BY \\ DAVID M. MOTTIER, \\ Professor of Botany in Indiana University.
}

With Plates XXVI and XXVII.

HISTORICAL.

W ITHIN the past few years, the discovery of an anomalous character in the embryo of some species of certain dicotyledonous families has stimulated interest in the question of the phylogeny of the Angiosperms, especially as these anomalies have been regarded as throwing some light upon the origin of the two divisions of the higher seed plants. The several observers have approached the subject from two standpoints, some dealing with the development of the embryo, while others have devoted themselves to the study of the comparative anatomy of seedlings. Of the publications that have recently appeared, dealing with the embryological evidence, that of Lyon ('01) was among the first. This observer has shown that Nelumbo lutea, one of the Nymphaeaceae, is fairly typical of the known anomalous dicotyledons. The development of the embryo is described under four stages, namely, the 'spherical stage,' the 'monocotyledonous stage,' the 'dicotyledonous stage,' and the 'mature embryo.'

The early development in Nelumbo results in a spherical embryo, consisting of several hundred cells. Growth now takes place such that a flattened or button-shaped mass of tissue results. From the distal side of this mass the plumule, or rather the apex of the stem, appears as a small protuberance, as does also the single primordium of the cotyledons, which arises as a crescent-shaped mound of tissue around the rear of the embryo, its wings (points of the crescent) extending forward even with the plumule. Judging from Lyon's Fig. 8 (1. c.), it seems that, at this stage, the plumule lies between the points of the crescentic cotyledonary primordium, but later it becomes situated within the space enclosed by the crescent. This closes the monocotyledonous stage. The subsequent development, immediately following, results in the cotyledonary primordium becoming two-lobed through the localization of growth at two nearly opposite points. With the final development of the embryo, these two lobes grow into the two large cotyledons. The sinuses between the cotyledons are not of equal

[Annals of Botany, Vo1. XIX. No. LXXVI. October, 1995.] 
depth, that representing the original cleft of the primordium being deeper. The two cotyledons have, therefore, a common base, having arisen from a common primordium. From these facts Lyon concludes that the embryo of Nelumbo lutea is monocotyledonous, placing the Nymphaeaceae among the Monocotyledons, in the series Helobieae.

In a preliminary note on the embryo of three species of Nymphaea, $N$. odorata, Ait., N. coerulea, Sav., and N. Lotus, L., Conrad ('02) asserts that the development up to the stage of the spherical embryo coincides with that of Nelumbo, as described by Lyon, but 'the spherical embryo, however, unlike that of Nelumbo, gives rise to two opposite and symmetrical outgrowths near its lower end. These become the two equal cotyledons. The intervening apical portion of the sphere becomes the plumule, with the rudiments of two unequally developed leaves. The basal portion of the sphere becomes the radical.'

In the same year Schmid ('02) gave an account, though somewhat incomplete as to certain details, of the embryology of two very remarkably anomalous dicotyledonous species, namely, Ranunculus Ficaria, L., and Corydalis cava, Schw. and Kte., one of the Fumariaceae. In Ramunculus Ficaria, after the embryo has become somewhat pear-shaped, growth takes place in such a manner that the central part of the apex, i. e. the truncated distal end of the embryo, seems depressed, while the edge grows up in the form of a thick ridge, or rampart, concave within and kidney-shaped in crosssection. This ridge Schmid calls the Anlage of one cotyledon. During the germination of the seed, this cotyledon unfolds as a single broad lamina with a rather deep notch at its apex. There is no trace of a second cotyledon. Schmid's Fig. $3^{8}, a-e$, shows that this cotyledon arises as a kidney-shaped primordium, which seems to be exactly like that giving rise to the two cotyledons in Actea alba and in other species to be mentioned later on. The same origin is figured also for the single cotyledon of Bunium Bulbocastanum, one of the Umbelliferae. In Corydalis cava the cotyledon arises as in Ramunculus Ficaria. Here the stem-apex is pushed to one side by the terminal position taken by the cotyledon. As in Ramunculus Ficaria, the base of the cotyledon is crescentic in cross-section, thus appearing with a narrow channel or groove down one side (Schmid, 1. c., Fig. I6). This condition resembles a cotyledonary tube open on one side. While Schmid regards this structure as one cotyledon, he states on p. 214 (1. c.) that the end of this cotyledon is slit near the apex, giving reference to his Fig. 49. Judging from this figure and from the fact that, in a number of other plants, the two unquestionable cotyledons have a single primordium, and inasmuch as Schmid has not given a more complete history of the embryo, it does not seem improbable that we have here two cotyledons with a common base, or in which one sinus is very much deeper than the other; but as the writer has not examined this species, he prefers 
to withhold judgement in the matter. It may be remembered that in two other species of Corydalis studied by Schmid, C. nobilis and C. lutea, the embryo is dicotyledonous, but these species do not form tuberous stems, a phenomenon that will receive further attention in a later paragraph. Schmid speaks of these plants as pseudo-monocotyledons, but he does not discuss the question of phylogeny. In Ranunculus Ficaria, Eranthis hiemalis and Corydalis cava, the embryo, which is incompletely developed when the seed is ripe, continues its development after the latter falls from the plant, and this author carried out experiments which showed that the phenomenon in question is due rather to favourable physical conditions than to any specific property of the soil. Schmid's study tended to show that the anomalous character of the embryo is closely associated with a geophilous habit and a short and tuberous stem.

Cook ('02) states that only one cotyledon is present in Castalia odorata and Nymphaea advena, members of the Nymphaeaceae, as he did not find a bifurcation of the cotyledonary primordium, as described by Lyon ('01) for Nelumbo. Cook's investigation does not seem to have been very exhaustive. Series of transverse sections through the cotyledonary origin at several stages in its early development, which are so necessary for a definite conclusion, are not given. He concludes that the Nymphaeaceae should be classed among the Naiadales.

The same observer has shown that the embryo of Claytonia virginica ('03) is remarkably anomalous in character. The embryo of the mature seed possesses one large cotyledon, with only the mere rudiment of the second. The nature of the cotyledonary primordium is, however, not figured.

Contrary to Cook, Schaffner ('04) finds that, in Nymphaea advena, the cotyledons arise from a crescentic primordium, as described by Lyon for Nelumbo.

Working under the direction of the writer, Lewis ('04) made a careful study of the development of the embryo of three species of anomalous Dicotyledons, namely, Podophyllum peltatum, Caulophyllum thalictroides, and Feffersonia diphylla, of the Berberidaceae. In each case the cotyledonary primordium is a broad, crescentic ridge open at one side, which develops from the truncated distal end of the usually pear-shaped embryo. From the centre of the truncated end enclosed by the cotyledonary primordium, develops the plumule, or apex of the stem. This ridge soon bifurcates at a point opposite the opening or primary sinus to form the two lobes, the cotyledons. With further growth, the two sinuses become of almost equal depth, so that the older stages do not reveal the true nature of the origin of the cotyledons. In Podophyllum there is a rather long cotyledonary tube formed by the intercalary growth of the common base of the cotyledons.

Approaching the subject of the phylogeny of the Angiosperms, with the anatomy of seedlings as data, Miss Sargant has brought together in a 
very skilful manner an immense mass of facts, derived from a thorough study of the anatomy of a large number of seedlings, chiefly of the Liliaceae. As will be more explicitly indicated in a later paragraph, this observer regards the Angiosperms as monophyletic in origin, the Dicotyledons being the more primitive, from which the Monocotyledons have been derived.

\section{OBSERVATIONS.}

The writer's observations were made upon Actea alba (L.), Mill., Delphinium tricorne, Michx., Aquilegia canadensis, L., Syndesmon (Anemonella) thalictroides (L.), Hoffmg., of the Ranunculaceae, and Sanguinaria canadensis, L., and Stylophorum diphyllum, Michx., of the Papaveraceae. In all of these species the development of the embryo was carefully traced from a very young stage to that found in the ripe seed. Although all show certain well-marked anomalies in the origin of the cotyledons, yet it will be seen from what follows that a gradual transition from a clearly anomalous type to that which is typically dicotyledonous is to be found in the same family, and even in the same species of a genus. Owing to the fact that the anomalous character is more pronounced in certain individuals of Actea alba, a detailed account of the embryo in this species will be given first.

\section{Actea alba.}

No effort was made to find the earlier cell-divisions in the young embryo, as that part of the process was not considered important in this study. The youngest embryos observed in Actea are represented in Plate XXVI, Figs. 1 and 2. At this stage it is clear that the embryo consists of a short suspensor about two cells broad and a somewhat club-shaped or cylindrical body, as indicated in both longitudinal and transverse sections (Figs. I, 2, and 3). The cells of the suspensor are characterized by the presence of starch in greater or less abundance, while those of the rest of the embryo contain little or no starch. Whether Fig. 2 is an older stage than Fig. I, or merely a section at right angles to the plane of Fig. I, was not determined. Fig. 3 is a cross-section through the middle of an embryo of the stage shown in Fig. I. The superficial cells now undergo periclinal and anticlinal divisions, whereby the epidermis is differentiated, while the cells within divide in three planes (Fig. 4). With further growth the embryo becomes symmetrically pear-shaped (Fig. 5). The distal end is either nicely rounded as in the figure just mentioned, or it may be somewhat flattened. The suspensor has grown only a little. Its cells contain starch, although this substance is seen in a few neighbouring cells of the remaining embryo.

At this stage begins the development of the cotyledonary primordium. As the true and exact nature of this can be better ascertained in series of 
cross-sections taken at right angles to the longitudinal axis of the embryo, a series of outlines of similar sections of embryos in different stages of development will be given. These sections not only show the shape of the embryo, but also that part involved in the formation of the cotyledons, and the changes taking place in their early formation. Fig. I $7, a$ to $p$, includes the whole embryo, with the exception of the first two cells of the suspensor and fragments of some cells at the distal end. The sections of this embryo were cut 7.5 microns in thickness. $a$ to $k$ represent alternate sections; $l$ to $p$ successive sections. Sections $m$ to $p$ of this figure show unmistakably that the formation of the cotyledonary primordium involves almost the entire end of the pear-shaped embryo, and that this end grows out into a thick crescentic mound or ridge. The entire embryo at this stage (Fig. 6) is a pear-shaped object with a curved indentation on one side at the broad end, which extends quite, or nearly, to the centre. Fig. 6 was carefully constructed from the series of sections shown in Fig. I7. The anatomical details of the embryo at a slightly later stage, as seen in a transverse section passing through the base of the cotyledons and including the tip of the stem, are shown in Fig. 14. At this stage, and even earlier, the formation of the plerome-strands ( $p l$, Fig. 14) in each cotyledon is very evident, and the central position of the apex of the stem (st, Fig. I4) is clearly indicated. With further development of the embryo, growth becomes localized in the cotyledonary primordium in such a way that a cleft is formed exactly opposite the original sinus, as indicated in Fig. I9, $a-k$. In this manner the two opposite and symmetrical halves of the cotyledonary primordium develop into the two cotyledons. At the stage of development represented in Fig. 19, we have an embryo with two cotyledons possessing a common base, and in which one of the sinuses between the cotyledons is twice as deep as the other. A median longitudinal section of an embryo similar to that of Fig. 19, taken at right angles to the flat surface of the cotyledons, is shown in Fig. 7. In this and similar sections there is nothing to indicate definitely that the two cotyledons have arisen from a common primordium, for the figure seems to coincide in every respect with that from a typical dicotyledonous embryo. At this stage (Fig. 7), it will be seen that the plerome-strands in the cotyledons and hypocotyl are becoming well defined. The suspensor is short, being one or two cells wide at the free end, but more massive at its juncture with the body of the embryo. As the embryo continues its development in the seed, the inequality in the depth of the sinuses, as shown in Fig. 19, is maintained in some individuals until a later stage, but growth is such that this difference in depth is somewhat equalized when the seed is mature. However, in the ripe seed, embryos are frequently found in which the sinuses are of unequal depth, and we have then cases of anomaly of a pronounced character (Fig. 8). This figure was constructed in the same 
manner as Fig. 6, from an embryo of a mature seed. The sinuses are of unequal depth, the primary cleft being deeper. There is no protruding stem-apex or plumule. The cotyledons are crescentic in cross-section, being concave on the inner surfaces. There is no cotyledonary tube formed in Actea alba. Although the cotyledons have a common base, yet they cannot, as will be shown in the following paragraph, be regarded as one cotyledon which has bifurcated. Such an interpretation might be defensible if all embryos of Actea alba followed closely the line of development as detailed in the foregoing.

It will now be shown that there is in this species what may be reasonably regarded as typical dicotyledonous development. Instances were found in which the cotyledonary sinuses appear at about the same time. Fig. I $8, a-h$, represents in outline a series of transverse sections, beginning just below the base of the cotyledons. Of course it cannot be stated with absolute certainty that the cotyledonary primordium was not slightly crescentic in its earliest stage, but from younger stages of a similar condition, and from the evidence obtained in Syndesmon, to be mentioned below, it is highly probable that the primordia of the cotyledons were separate or nearly so. As in the former case, it will be seen from $b$, Fig. 18 , that the origin of the cotyledons involves almost the whole truncated end of the embryo. Fig. 16 , which is $b$, Fig. 18 , drawn in detail, shows the same condition of things as indicated in Fig. I4. Fig. $16, b$, is taken at a level corresponding with that of Fig. I4. In Fig. 18 is shown what is of frequent occurrence, namely, the unequal length of the two cotyledons. In several cases examined, both in Actea and in the other species to be mentioned later, the two cotyledons are not only of unequal length, but one may be more massive as well. Cases are also met with in which the embryo was obliquely symmetrical (Fig. 15). It may be mentioned further that, in ripe seeds of the same ovary, the embryos are frequently of different sizes, and may have attained appreciably different stages in development.

\section{Sanguinaria canadensis.}

The earliest stage observed in the development of the embryo of Sanguinaria canadensis is shown in Fig. 9, which is a median longitudinal section. At this stage the embryo is cylindrical, as shown in cross-section (Fig. IO), with a very short suspensor of about two or three cells. The cytoplasmic contents of the cells are regular and uniform, little or no starch being found in the embryo at this or later stages. The resemblance of this embryo to that of Monocotyledons in similar stages of development is noticeable, but no special significance can be attached to this fact. As has been pointed out in Actea alba, the immediate subsequent development results in a pear-shaped structure (Fig. 20, an outline of a median longitudinal section). As this figure indicates, the suspensor is short, merging 
insensibly into the remainder of the embryo, unless the three cells mentioned above are to be regarded only as the suspensor. In Fig. 20, the embryo shows a slight depression in the centre of the broad, flattened end. The part surrounding the depressed centre now grows faster to form the primordium of the cotyledons. Serial cross-sections of a slightly older stage (Fig. 2I) show beyond a doubt that the thick, crescentic ridge-like primordium of the cotyledons obtains here as in Actea. Fig. $2 \mathrm{I}, a$, which is the first successive section ( 7.5 microns in thickness) below this primordium, shows that the embryo is somewhat flattened at right angles to the plane of the cotyledons, a phenomenon of usual occurrence in the embryos of the several species with which we are dealing. Later the embryo becomes more cylindrical. In $c$, Fig. 21 , it will be seen that the apex of the stem is recognized as a very small rounded protuberance exactly at the centre of the space enclosed by the cotyledonary primordium. Fig. 22, $a-d$, is a series similar to Fig. 2I, taken from an embryo only a little further developed. Section $d$ of this figure includes the distal end of the embryo, and shows what would be seen by looking directly upon this end. The bifurcation of the primordium opposite the primary sinus is just perceptible in the section, being indicated in the figure by dotted lines. The apex of the stem can also be recognized as a small rounded elevation. A median longitudinal section, at right angles to the plane of the cotyledons, is shown in Fig. 23. It is apparent now that the growth of the embryo of Sanguinaria canadensis, immediately following the pear-shaped stage, results in a very marked increase in the width of the distal end with scarcely any increase in length. The suspensor is comparatively very short. With the final development of the embryo, culminating in the ripe seed, the same proportion of increase in size is maintained (Fig. 24, $a-h$ ). $a$ to $c$ of this figure represent consecutive sections, beginning at the base of the cotyledonary primordium, while $d$ to $h$ are alternate sections. It is clear from this series, which was made from an embryo in the ripe seed, that the common base of the two cotyledons has undergone intercalary growth, the result of which is that the primary sinus is deeper $(22$ microns $)$ than the other. The apex of the stem, although central, extends slightly upward, as if adnate to that part of the cotyledonary primordium directly opposite the primary sinus. The cotyledons are crescentic in cross-section at the base, but become gradually more flattened near their tips. Fig. 25 has been constructed from all the sections of the embryo, represented only in part in Fig. 24, and it shows the condition of the embryo in the ripe seed. We have therefore in the mature seed of Sanguinaria an embryo broader than long, in which the difference in depth of the two sinuses of the short and widely divergent cotyledons is only slight. The suspensor is short, consisting of only a few cells. The apex of the stem is recognizable as a small, rounded protuberance at the centre of the area surrounded by the 


\section{Mottier. - The Embryology of some Anomalous Dicotyledons.}

base of the cotyledons. In conclusion it may be said that the embryo of Sanguinaria canadensis shows a well-marked, though not very pronounced, degree of anomaly in the development of the cotyledons, and that this anomalous character may persist in the embryo found in the ripe seed. Variations in the degree of anomaly are also to be observed.

\section{Stylophorum diphyllum.}

The development of the embryo of Stylophorum is similar to that of Sanguinaria; consequently attention will be directed to certain features only. The earlier stages, in so far as they were observed, were similar to those of Sanguinaria. Beginning with the development of the cotyledons, we find that they originate in the familiar crescent-shaped ridge (Fig. 27, $a-f$ ). In this figure $I$ have indicated the plerome of the cotyledons and hypocotyl by broken lines. After what has been said concerning Sanguinaria, this series of outline drawings is self-explanatory. It is worthy of note, moreover, that the anomaly, in so far as it is present, is even less pronounced in Stylophorum, the bifurcation of the crescentic primordium occurring earlier, and in the mature embryo the depth of the sinuses is almost, if not quite, equal. Not only this, but cases were observed (Fig. 26, $a-c$ ) in which no anomaly was present. In these we have before us apparently the development of a typical dicotyledonous form. In such a typical dicotyledonous form, however, it must be remembered that, as stated in a foregoing paragraph, the primordia of the cotyledons involve nearly the whole end of the embryo as in the most pronounced anomalous types (Fig. 26, $a-b$ ). The difference between Figs. 26 and 27 lies mainly in the fact that, in the former, the primordium bifurcates to form the two sinuses at exactly the same time, and it is doubtless proper to speak of primordia rather than of a single primordium; but these primordia are not so distinctly isolated as one might suppose from the descriptions usually given of the origin of the cotyledons. In the nearly mature seed, although the cotyledons are relatively short, the embryo is much less in the form of a low broad goblet than that of Sanguinaria, i. e., the longitudinal axis is greater than the transverse (Fig. 28). The suspensor is also short. Stylophorum diphyllum may be regarded, therefore, as typically dicotyledonous, showing a tendency only to a slightly anomalous character in the formation of the cotyledons.

\section{Delphinium tricorne.}

We shall now follow the development of the embryo in two or three more species of the Ranunculaceae for comparison with Actea alba. Agreeing with the other species already described, the pear-shaped embryo of Delphinium tricorne is somewhat flattened at right angles to the plane of the cotyledons (Fig. 29). The first indication of the cotyle- 
donary primordium appears in the form of a narrow, elongated depression, which is just perceptible at the truncated end, extending from one side to the centre. The shaded part of $b$, Fig. 29, represents this depression. The primordium here is more nearly kidney-shaped than crescentic. Fig. II represents a more detailed drawing of $a$, Fig. 29. The larger cells in the centre indicate the apex of the stem. There is at this stage no indication of the plerome strands; these appear later, as shown for the species already described.

As growth continues, the primordium becomes typically crescentic, and the embryo is more cylindrical (Fig. 3०, a-e, representing alternate sections of a part of the embryo). Whether the embryo represented in this figure was not cylindrical from the beginning cannot be stated. However, this matter is unimportant. During succeeding development, the crescentic primordium soon bifurcates, but the difference in depth of the two sinuses is increased rather than diminished, so that in the mature seed the anomaly is more pronounced (Fig. $3 \mathrm{I}, a-g$ ). This figure does not include all of the embryo beyond the base of the cotyledons, but only alternate sections from that point to the bottom of the second sinus. This series of sections, taken from an embryo in the mature seed, shows that a cotyledonary tube is present, a phenomenon that has been reported for two other species of Delphinium, D. mudicaule, and D. hybridum (Sargant, '03, p. 73). Fig. 32 is intended to show the form of the embryo as it is in the mature seed. As it was found impracticable to dissect out the embryo on account of its small size and the firmness of the endosperm, this figure was constructed, as in the other species, from a complete series of cross-sections, and the proportions are reasonably accurate. It may be noted that the embryo has a relatively longer hypocotyl than in Actea, and the cotyledons diverge towards the apex. These are crescentic in cross-section. The two sinuses are of unequal depth, and the cotyledonary tube is formed by the intercalary growth of the common base of the cotyledons. In Fig. 32, the relative depth of this tube is indicated by the dotted line, which shows also the outline of the space enclosed by the cotyledons. In Delphinium, as well as in the other species under consideration, there is no plumule in the ordinary conception of that term. Here the apex of the stem does not even project as a recognizable protuberance, at least, so far as my observations have extended.

\section{Aquilegia canadensis.}

The youngest stage of the embryo of Aquilegia observed was an elongated cylindrical structure, somewhat bent near the middle, and possessing a suspensor of three or four cells (Fig. 12). At this stage, it was not possible to determine the exact limits of the suspensor. With 
subsequent growth the pear-shaped form is assumed, and the beginning of the cotyledons is soon manifested (Fig. 33, $a-d$, representing four consecutive sections only of the embryo). A comparison of this figure with figures 29 and 30 will show the similarity in the origin of the cotyledons with that in Delphinium. It is evident that, in this case, the primordium was kidney or bean-shaped, but as it bifurcates soon after being laid down, the anomalous character can be said to exist only as a mere trace. This is made clear in Fig. 34, $a-f$. In this embryo the cotyledonary primordia seem to have arisen separately, and not as one piece, the two involving, however, nearly the whole end of the embryo. In $d$, Fig. 34, the base of one of the young cotyledons is more massive than the other. In fact, in all species of the two families examined, it not infrequently happens that one cotyledon is larger than the other, being sometimes longer or thicker (see also Fig. I8). Fig. 35, $a-g$, refers to an embryo of a mature seed. This series is not consecutive throughout, one or more sections being omitted between $b$ and $c, d$ and $e$, and $f$ and $g$. The base of each cotyledon is almost cylindrical, a feature in which Aquilegia differs from the other genera mentioned. The nature of the embryo in the mature seed is shown in Fig. 13. This figure was constructed from a series of cross-sections as mentioned for the preceding species, with the exception that the middle portion of each cotyledon has been omitted in order to show that, while the cotyledons are somewhat cylindric at the base (e, Fig. 35), they soon become concave within, and consequently crescentic in transverse section. No indication of a plumule was observed in the embryo of the ripe seed.

\section{Syndesmon thalictroides.}

Measured by the standard of endosperm-formation, the development of the embryo in Syndesmon is relatively slow; for, in a large percentage of the preparations made from the ripe seed, the cotyledons had just put in an appearance. In some cases no indication of these were to be seen, while in others the cotyledons had attained a length equal to about one-third of the length of the entire embryo. The origin of the cotyledons seems to be typically dicotyledonous, even more so than in Aquilegia, so that it was not considered necessary to give illustrations. In only one case was the slightest indication of an anomaly observed. The first appearance of the cotyledonary primordia, it may be added, is almost identical with that in Aquilegia in which no anomaly was observed, and this fact is probably due more to a similarity in habit than to genetic relationship. The suspensor of the embryo seems to be a little more massive than in the species hitherto mentioned, the whole embryo, however, resembling that of Aquilegia. 


\section{THEORETICAL.}

It now becomes necessary to examine the evidence revealed by a study of the embryology of the several anomalous dicotyledons, in order to show what light knowledge thus obtained throws upon the question of phylogeny of the Angiosperms, and what the relative value of such knowledge is as compared with that derived from other sources.

Any consideration of this subject brings the investigator face to face with the ever recurring questions, which have received various answers at the hands of the most competent observers: Have the Angiosperms been derived from the Gymnosperms or directly from a pteridophytic ancestor? Have the two classes of Angiosperms had a common or an independent origin? If monophyletic, which are the more primitive, Monocotyledons or Dicotyledons?

It must be admitted that many, perhaps the majority of the known facts, may be reasonably interpreted in the light of opposing doctrines. In fact, this has been done in the several theories that have been advanced in the past. No matter what answer may be given to the first of these questions, the status of the other two will remain about the same. Some observers may prefer to adhere to the older view, that the Angiosperms have been derived from the Gymnosperms, with Gnetum as the nearest living representative of a transitional condition, yet others will undoubtedly be inclined to seek the ancestry of the Angiosperms among the Pteridophytes. The dicotyledonous character of certain Gymnosperms has lost much of the importance formerly attached to it in the consideration of the origin of the Angiosperms, since it has become known that very important similarities in structure have appeared independently in different organisms widely separated in phylogeny, and because of the incomplete geological evidence in regard to Gnetum. The writer prefers to regard the gymnospermous origin of the higher seed plants as less probable, and believes that the most important evidence points to a pteridophytic ancestry. Now, if we assume that the Angiosperms have sprung from the Pteridophytes, we have in Isoetes what may be regarded as a transitional condition leading to the Monocotyledons, and in Selaginella certain embryological characteristics suggestive of a dicotyledonous nature. Professor Campbell ('91) has shown in his thorough and exhaustive study of Isoetes the striking embryological resemblance between this genus and certain Monocotyledons, and the facts there set forth point strongly to the great antiquity of the monocotyledonous ancestors. Whether the evidence will justify the assumption of a separate pteridophytic ancestry of the two classes of Angiosperms may be seriously questioned, especially if we do not regard the character of the female gametophyte and the seed-habit of equal phylogenetic value. The writer 
is quite willing to admit the probability of the seed-habit as having arisen independently in Gymnosperms and in the Angiosperms, but it is certainly difficult to understand how a structure like the embryo-sac, which is exactly alike in the vast majority of both groups of Angiosperms, could have arisen otherwise than from a common ancestor. The embryo-sac is certainly as deeply seated as any known structure, and if morphological characters have any great value in determining phylogeny, the embryosac tells no uncertain story. This may not be said with equal emphasis for the seed-habit or for the organs of an embryo. The embryo in the mature seed of Zamia, for example, bears a marked resemblance to that of a Dicotyledon, yet the difference in the early development of each is very great. Furthermore, it may be said that the first step toward the seed-habit was taken when the female prothallium of a Pteridophyte was retained within the macrospore, and the greatest progress toward seed formation found in any living Pteridophyte is the female prothallium with its enclosed embryo in the macrospore of Selaginella and Isoetes. Let it be understood, however, that the writer does not imply that the change from the habit now existing in Selaginella or Isoetes to an angiospermous seed has been a direct one, but conditions like these seem to indicate the probable line of development leading towards seed-formation.

The embryo-sac is still our greatest stumbling-block, and, as stated above, if deep-seated morphological characters count for much, Monocotyledons and Dicotyledons have had a common ancestor, or their parent stocks were very closely related. Probably the majority of recent writers agree in the monophyletic theory of the origin of the Angiosperms, but they differ as to which of the two classes is the more primitive, and as to the relative value of the evidence brought forth in support of their respective views.

Lyon ('01), in a well-written essay, argues in favour of the monophyletic theory, regarding the Monocotyledons as the more primitive stock from which the Dicotyledons have been derived. The monocotyledonous stock, according to his view, is derived from pteridophytic ancestors, the foot of the embryo of a Fern being homologous to the cotyledon. 'It (i. e. the foot) is to the pteridophyte embryo in a simple way what the cotyledon is to the embryo of a Monocotyledon, and is in fact to be considered as a more primitive type of cotyledon' (1. c., p. 66). The period of life of the sporophyte of Bryophytes and Pteridophytes within the calyptra is regarded as comparable to the intra-seminal life of the angiospermous embryo, and the single cotyledon of the monocotyledonous embryo is considered as having bifurcated to give rise to the two cotyledons in a manner similar to the bifurcation of the cotyledonary primordium of Nelumbo. Lyon's point of view is well stated, and his theory is suggestive, but it seems to the writer that the facts do not indicate that the foot has undergone the morphological 
changes demanded by the theory. The writer feels that a detailed statement explanatory of his view would far exceed the purpose of this paper, and he prefers to let the matter stand at present with the above expression of his opinion.

An argument in favour of the monophyletic origin of the Angiosperms has also been advanced by Miss Sargant ('03), but this observer considers the Dicotyledons as the more primitive stock from which the Monocotyledons have been derived, suggesting that the anomalous character of certain dicotyledonous embryos indicates the probable line of transition. Miss Sargant approaches the subject from the standpoint of the anatomy of seedlings, examining into the anatomical details of a large number of species, chiefly of the Liliaceae, and bringing the great mass of details together in a very careful and praiseworthy manner.

Using Anemarrhena as a type, she finds two opposed vascular bundles in the terminal cotyledon. These extend down into the hypocotyl, where each divides, and the four plerome-strands thus formed are continuous with those of the tetrarch primary root. This behaviour of the bundles suggests, it is pointed out, that the single cotyledon of Anemarrhena is the homologue of two, which were separate in some dicotyledonous ancestor. It is further suggested that Eranthis hiemalis, one of the Ranunculaceae, may be illustrative of such an ancestor.

A summary of the views of Coulter and Chamberlain in regard to the phylogeny of the Angiosperms is expressed by these authors (Morphology of Angiosperms, pp. 287, 288) as follows:- 'The Monocotyledons and Dicotyledons represent two independent lines derived directly from Pteridophyte stock, probably from the Filicales. At the same time, the arguments in favour of the monophyletic origin of Angiosperms are strong; and if this view be accepted, the derivation of Monocotyledons from primitive Dicotyledons seems to rest on stronger evidence than the reverse relationship. It must also be said that the Gymnosperm origin of Angiosperms is not to be discredited so much now as formerly.'

With the brief statement of the two views concerning the relative antiquity of Monocotyledons and Dicotyledons, under the assumption of a monophyletic origin, we are now prepared to examine more directly the evidence furnished by the embryology of anomalous Dicotyledons in the light of recent investigations. In basing conclusions upon morphological data, indeed the most reliable of all, the first requisite is to determine whether the structures dealt with represent primitive or derived characteristics, as it is upon this point, of course, that observers will be found to differ most, especially in the presence of a few isolated facts. With a detailed knowledge of only a few anomalous Dicotyledons, observers were quick to regard this character as primitive, and consequently conclusions were easily reached. With the crescent-shaped primordium of the cotyledons as 
found in certain Nymphaeaceae and Ranunculaceae as a basis, it is easy to show how, during phylogeny, this primordium, by a bifurcation opposite the primary sinus, might have given rise to two cotyledons. Or if the primordium should develop as one piece without undergoing a bifurcation, the resulting cotyledon might then be looked upon as a union of two cotyledons. The former is the view held by Lyon, the latter, the interpretation given by Miss Sargant.

As a matter of fact, the writer believes that the investigations of Schmid ('02) on species of Ramunculus and Corydalis, and the results of similar studies upon species of the Ranunculaceae and Papaveraceae as detailed in the foregoing paragraphs, together with the observations of Lewis ('04) on Podophyllum and Feffersonia, show conclusively that the anomalous character of the embryo is not a primitive, but purely a derived condition. In the genera forming the basis of this paper, it is seen that there is a transition from the anomalous embryo to that which is typically dicotyledonous, and that this transition is seen in different species of the same genus. Schmid points out that, in Ramunculus Ficaria and Corydalis cava, only one cotyledon develops, leaving us to infer that the second is not formed, but in both Corydalis nobilis and $C$. lutea two cotyledons are typically formed. Are we to infer, therefore, that Corydalis cava represents a primitive condition in the development of its embryo, while C.nobilis and C. lutea do not? Schmid states further that the seedling of C. cava forms a tuberous stem, while $C$. nobilis and $C$. lutea do not. Cook ('03) has shown also that in Claytonia virginica, a geophilous plant, only one cotyledon develops, the other remaining abortive. It is probably true without exception that dicotyledonous plants possessing anomalous embryos are either partly or wholly geophilous in habit, having stems either in the form of a rhizome, tuber, or a short, squat axis. In other words, the anomalous character is in all probability correlated with an hypogean habit. There can be no doubt, I think, that the cotyledonary tube is merely an adaptation to a geophilous habit, as seems to be shown in all plants possessing the same. If, on the contrary, the cotyledonary tube and the anomalous embryos represent primitive characters, then it must be shown that the geophilous habit is a primitive condition, but the writer does not believe that that has been done up to the present, at least. If the conclusion arrived at here is correct, anomalous Dicotyledons throw little or no light upon the relative antiquity of the two classes of Angiosperms ; for as embryological evidence is of greater value than anatomical, it seems as reasonable to conclude, using the anomalous character as a basis, that Dicotyledons have been derived from Monocotyledons as the reverse. 


\section{SUMMARY.}

Of the species investigated, all except Stylophorum diphyllum and Syndesmon thalictroides show a certain well-marked anomalous character in the development of the embryo of numerous individuals, while in others the anomaly may be only slightly manifested. In Stylophorum and Syndesmon the embryo is typically dicotyledonous, except in certain individual cases observed in which slight anomalies were present.

In the anomalous forms in question, the primordium of the cotyledons arises as a thick crescent-shaped ridge of tissue, open at one side, growing out of the truncated end of the pear-shaped embryo. The opening of the crescent becomes the primary sinus of the cotyledons. With further growth, the primordium bifurcates at a point opposite the primary sinus and thus forms the two cotyledons. With subsequent growth of the embryo, the depth of the two sinuses may or may not become equalized.

The anomalous character represents a derived and not a primitive condition. Consequently the anomalous Dicotyledons do not show that one class of Angiosperms was derived from the other.

\section{LITERATURE.}

Campbell, D. H. ('91): Contributions to the life-history of Isoetes. Ann. Bot., v, I89i, pp. $23^{I-2} 5^{8}$.

('02): On the affinities of certain anomalous Dicotyledons. Am. Nat., xxxvi, 1902, pp. 7-1 2 .

Conrad, H. S. ('02): Note on the embryo of Nymphaea. Science, xv, 1902, p. 316.

Cook, M. T. ('02): Development of embryo-sac and embryo of Castalia odorata and Nymphaea advena. Bull. Torr. Bot. Club, xxix, 1902, pp. 2 I I-220.

('03): The development of the embryo-sac and embryo of Claytonia virginica. Ohio Nat., iii, 1903, pp. 349-353.

LEwis, C. E. ('04): Studies on some anomalous dicotyledonous plants. Bot. Gaz., xxxvii, 1904, pp. $127-138$.

Lyon, H. L. ('01): Observations on the embryogeny of Nelumbo. Minn. Bot. Stud., ii, I9oI, pp. $643-655$.

('01): The phylogeny of the cotyledon. Postelsia, I90I, pp. 55-86.

SARGANT, ETHEL ('03): A theory of the origin of Monocotyledons founded on the structure of their seedlings. Ann. Bot., xvii, I903, pp. I-92.

Schaffner, J. H. ('04): Some morphological peculiarities of the Nymphaeaceae and Helobiae. Ohio Nat., iv, 1904, $83-89$.

Sснмг, B. ('02): Beiträge zur Embryo-Entwickelung einiger Dicotylen. Bot. Zeit., 1x, 1902, pp. 207-230. 


\title{
EXPLANATION OF FIGURES IN PLATES XXVI AND XXVII.
}

\author{
Illustrating Professor Mottier's paper on the Embryology of Anomalous Dicotyledons.
}

Unless otherwise stated, all figures were drawn from carefully prepared microtome sections with the aid of the camera lucida.

Figs. I-8. Actea alba.

Figs. I and 2. Longitudinal sections of young embryos, the cells of the suspensor contain starch. $\times 4^{2} 5$.

Fig. 3. A transverse section throngh the middle of an embryo in the stage of development of Fig. I. $\times 4^{2} 5$.

Fig. 4. Median longitudinal section. The embryo is becoming pear-shaped. The suspensor is short, its cells contain starch. $\times 4^{2} 5$.

Fig. 5. A typical pear-shaped embryo just prior to the appearance of the cotyledonary primordium. $\times 425$.

Fig. 6. View of an embryo after the appearance of the cotyledonary primordium, which is a thick crescentic ridge formed at the margin of the truncated distal end. The opening of the crescent faces the observer. This opening, or primary sinus, is an indentation at one side of the embryo extending towards the centre, but becoming shallower at that point. This figure was constructed from the series of cross-sections shown in Fig. I 7 .

Fig. 7. Longitudinal section of an embryo from a nearly mature seed, at right angles to the plane of the cotyledons. Only one cell of the suspensor is omitted from the drawing. The plerome strands in hypocotyl and cotyledons are being differentiated. $\times \mathbf{2 5}$.

Fig. 8. View of an embryo from a mature seed. The cotyledonary sinuses are of unequal depth, the primary sinus which is nearest the observer being deeper. Constructed in the same manner as Fig. 6 .

Figs. 9, I0. Sanguinaria canadensis.

Fig. 9. Median longitudinal section through young cylindrical embryo with very short suspensor. $\times 4^{2} 5$.

Fig. 10. Transverse section through a similar embryo. $\times 425$.

Fig. II. Delphinium tricorne. Transverse section through broad end of pear-shaped embryo before the appearance of the cotyledonary primordium. Tissues undifferentiated. $\times 300$.

Figs. I2, 13. Aquilegia canadensis.

Fig. I 2. Longitudinal median section through young embryo. $\times 425$.

Fig. I3. View of embryo from mature seed. The middle part of each cotyledon is omitted. Constructed in the same manner as Figs. 6 and 8.

Figs. 14-19. Actea alba.

Fig. I4. Transverse section through the base of the cotyledonary primordium, showing primary sinus; st. apex of stem; $p l$. plerome strands. $\times 300$.

Fig. 15. Section similar to Fig. I4, but from an embryo showing no anomaly. The two sinuses of the cotyledons were formed simultaneously. This embryo was obliquely symmetrical. $\times 300$.

Fig. I6. Similar to Fig. I5, but from a symmetrical embryo.

Fig. 17. A series of transverse sections of an embryo shown in outline, at the time of the appearance of the cotyledonary primordium. Sections were cut 7.5 microns in thickness. $a-k$, alternate sections; $l-p$, successive sections. $\times 300$.

Fig. 18, $a-h$. A series of transverse sections beginning just below the cotyledons. This embryo showed no perceptible anomaly; one cotyledon, however, was longer than the other. $\times$ I 25.

Fig. 19, $a-k$. Similar series, but of an older embryo. The anomalous character is typical and the most pronounced at this stage for this species. $\times 180$.

Figs. 20-25. Sanguinaria canadensis.

Fig. 20. Outline of a median longitudinal section of a pear-shaped embryo. The slightly depressed centre is an indication of the beginning of the cotyledonary primordium. $\times$ I80. 
Fig. 2I, $a-c$. Three cross-sections, beginning below the primary sinus of the cotyledonary primordium. The stem apex is only a perceptible protuberance at the centre of the space enclosed by the cotyledonary primordium. $\times 125$.

Fig. 22, $a-d$. Successive sections of an embryo, beginning below cotyledonary primordium. $d$ includes the end of the embryo, giving the view obtained by looking directly at the end. The second sinus and the tip of the stem indicated by the broken lines are just perceptible. It is seen that the primary sinus is deeper, and a well marked anomaly exists. $\times 125$.

Fig. 23. Outline of a longitudinal section of an embryo similar to the above. $\times$ I25.

Fig. 24, $a-h$. Series of alternate sections of an embryo from a mature seed, beginning below the primary sinus. The common base of the two cotyledons is quite marked. The base of each cotyledon is crescentic in cross-section, but their diverging ends become flattened as shown in $g$ and h. $\times 125$.

Fig. 25. View of an embryo constructed from the same series of sections shown in part in Fig. 24. The tip of the stem is a very small protuberance. This is the only indication of a plumule.

Figs. 26-28. Stylophorum diphyllum.

Fig. 26, $a-c$. Three transverse sections through base of cotyledons of an embryo from a nearly mature seed. The two cotyledonary sinuses are of equal depth, and the two primordia seem to have been separate from the beginning, if there is such a thing as quite separate primordia. In $a$, the plerome of the stem and cotyls are indicated by broken lines. The stem apex is quite central. $\times \mathrm{I} 25$.

Fig. 27, a-f. Series of an embryo similar to the foregoing. A slight anomaly is manifested here. The stem apex is central, although appearing $(d)$ slightly adnate to the base of the cotyledons below the secondary sinus. $\times 125$.

Fig. 28. Outline of a longitudinal section of an embryo. $\times 125$.

Figs. 29-32. Delphinium tricorne.

Fig. 29, $a-b$. Two consecutive transverse sections from the broad end of a pear-shaped embryo in which the kidney-shaped cotyledonary primordinm has just appeared. The primordium comprises almost the whole end of the embryo. $\times$ I 25.

Fig. $30, a-e$. Series from an older embryo. The anomaly is quite well marked. $\times 125$.

Fig. $3 \mathbf{I}, a-g$. Series (alternate sections) from an embryo of a ripe seed, beginning at the base of the cotyledons, $a$, and extending to secondary sinus, $g$. The anomaly is marked; the common base of the cotyledons by intercalary growth has formed a cotyledonary tube. $\times 125$.

Fig. 32. View of embryo constructed from same embryo as Fig. 3I. The broken line indicates depth of cotyledonary tube.

Figs. 33-35. Aquilegia canadensis.

Fig. 33, $a-d$. Four consecutive sections including base of cotyledons. The cotyledonary primordium seems to have been kidney-shaped. $\times$ I 25.

Fig. 34. From an embryo similar to the preceding; anomaly less marked. $\times 125$.

Fig. 35, $a-g$. Sections of an embryo from mature seed. $c, d$ and $e, f$ are consecutive. The base of each cotyledon is somewhat cylindrical. $\times 125$. 
Annats of Botany,

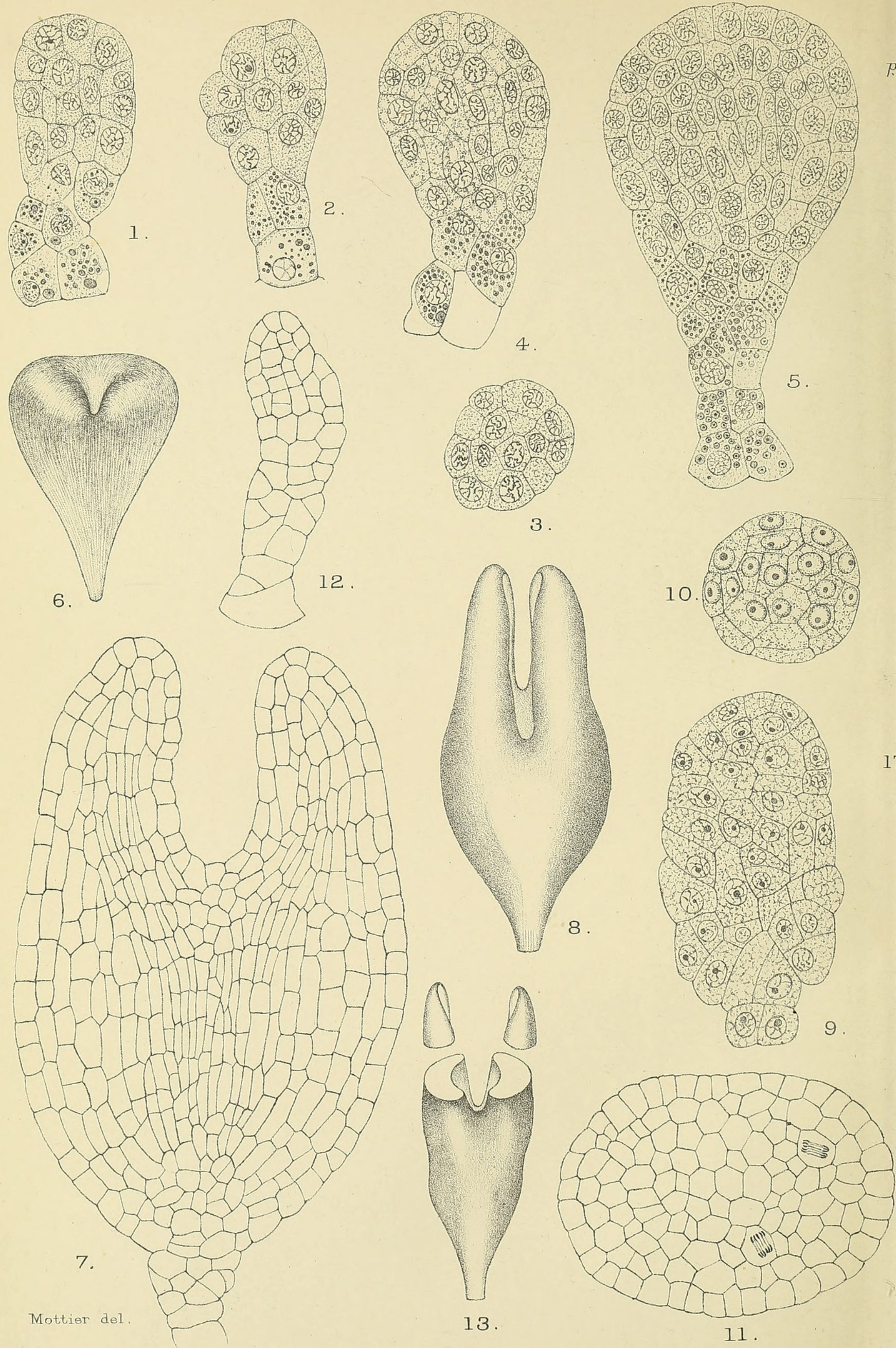

MOTTIER, — EMBRYOLOGY OF DICOTYLEDONS 


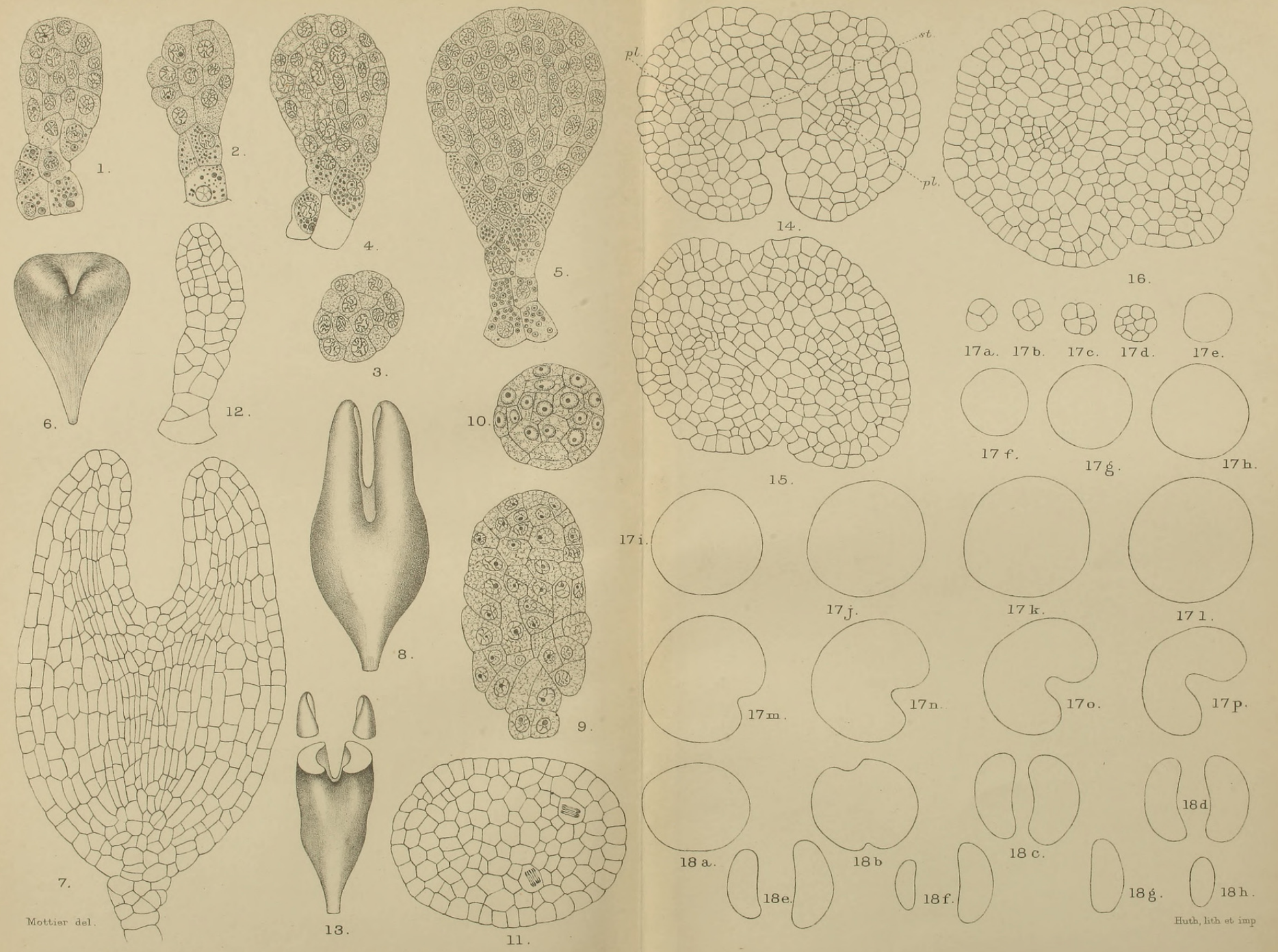

MOTTIER, — EMBRYOLOGY OF DICOTYLEDONS 
Annals of Botany,
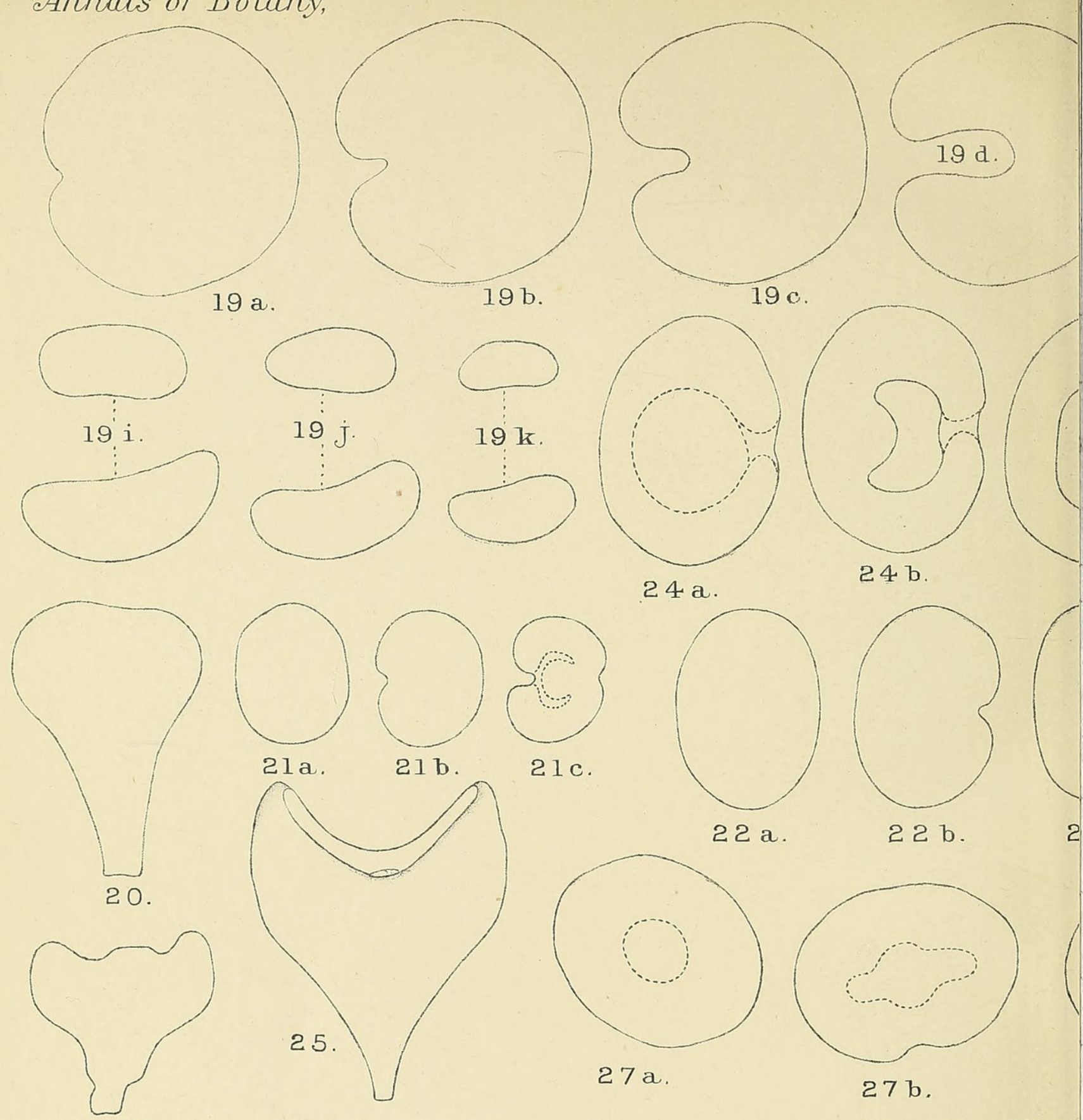

$$
24 a \text {. }
$$

23.

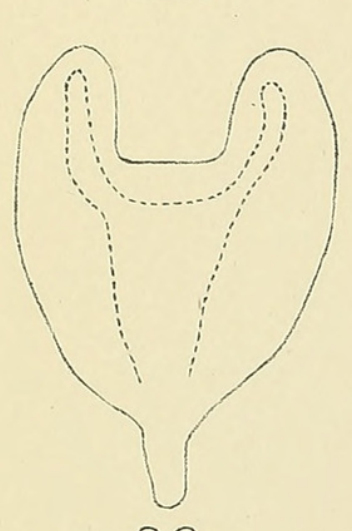

28.

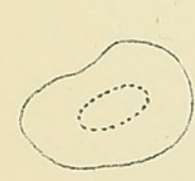

$34 \mathrm{a}$. Mottier, del

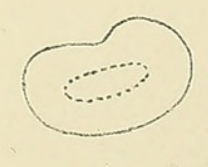

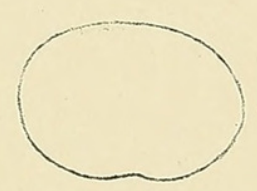

$29 \mathrm{a}$.

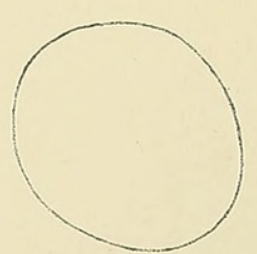

$31 \mathrm{a}$

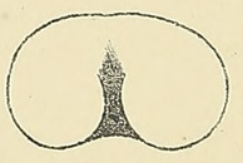

$29 \mathrm{~b}$.

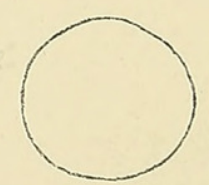

$30 \mathrm{a}$.

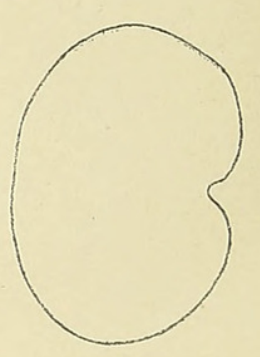

$22 \mathrm{~b}$.

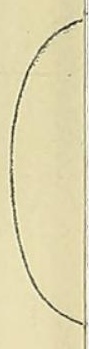

2

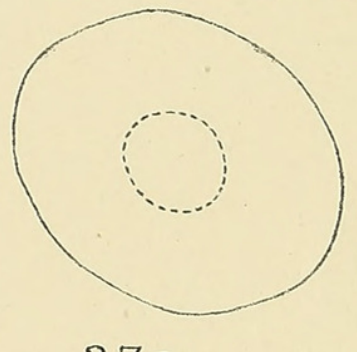

$27 \mathrm{a}$

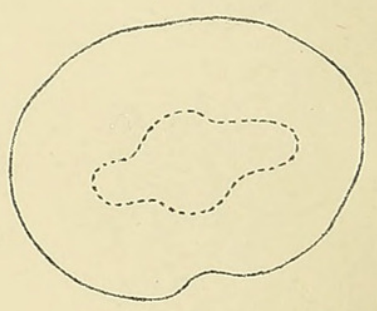

$27 \mathrm{~b}$.
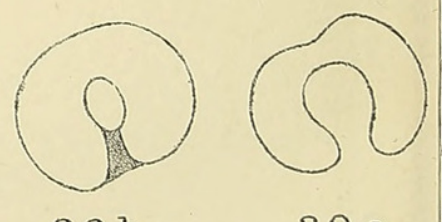

$30 \mathrm{c}$. 


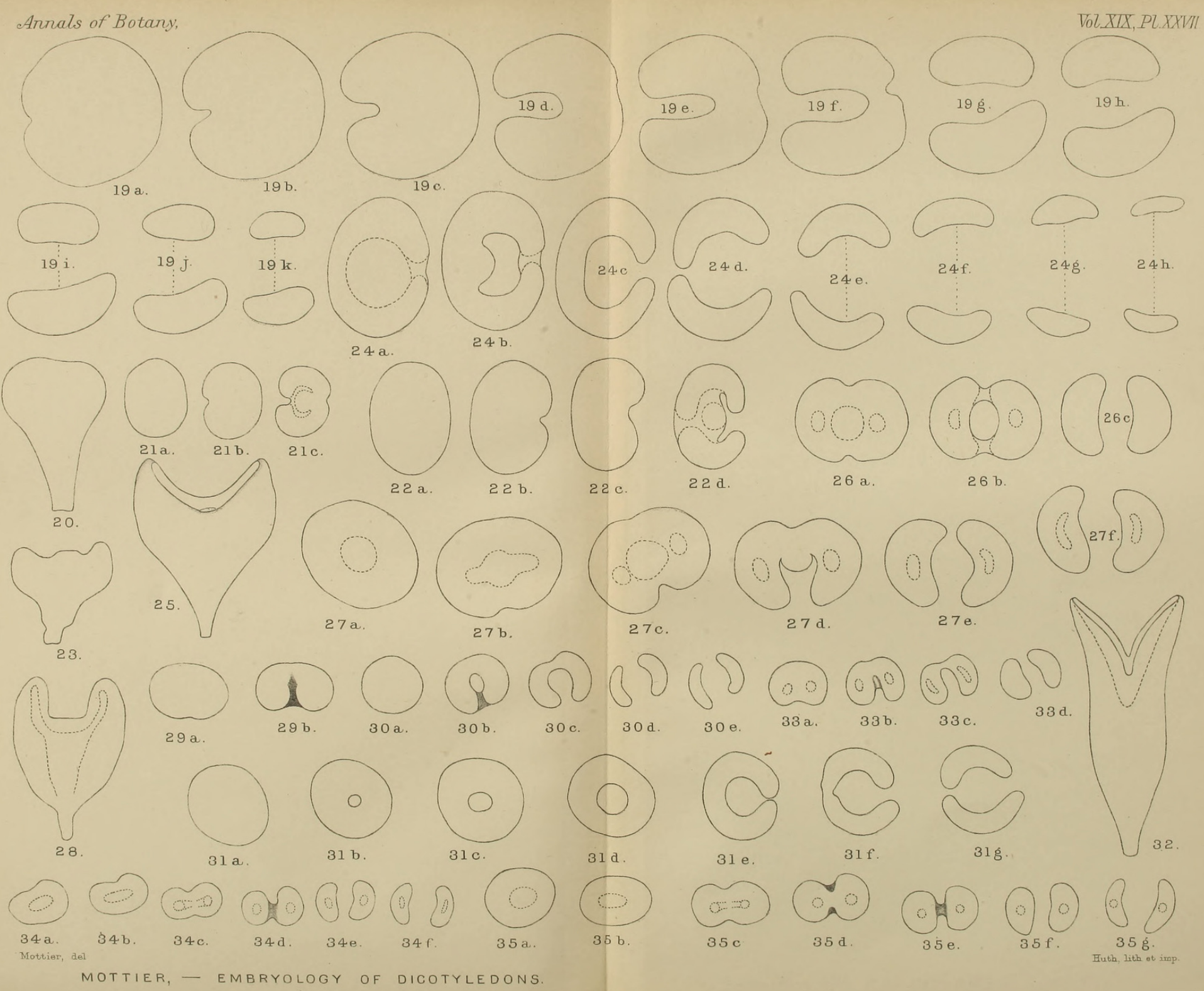




\section{$2 \mathrm{BHL}$ Biodiversity Heritage Library}

Mottier, David M . 1905. "The embryology of some anomalous dicotyledons." Annals of botany 19, 447-463.

https://doi.org/10.1093/oxfordjournals.aob.a089013.

View This Item Online: https://www.biodiversitylibrary.org/item/233541

DOI: https://doi.org/10.1093/oxfordjournals.aob.a089013

Permalink: https://www.biodiversitylibrary.org/partpdf/318811

\section{Holding Institution}

Smithsonian Libraries

\section{Sponsored by}

Biodiversity Heritage Library

\section{Copyright \& Reuse}

Copyright Status: Not in copyright. The BHL knows of no copyright restrictions on this item.

This document was created from content at the Biodiversity Heritage Library, the world's largest open access digital library for biodiversity literature and archives. Visit BHL at https://www.biodiversitylibrary.org. 